\title{
Trabalho em plataformas digitais: perspectivas desde o Sul global
}

\author{
Ludmila Costhek Abílio \\ Henrique Amorim* \\ Rafael Grohmann ${ }^{* * *}$ (D)
}

\section{Resumo}

O dossiê Trabalho em plataformas digitais: perspectivas desde o Sul global se organiza com o objetivo de trazer contribuições para as análises que se fazem a partir da periferia e reconhecem sua centralidade nos fenômenos globais contemporâneos. Trata-se, portanto, de pesquisas que incorporam as estruturas específicas do trabalho na periferia em sua análise, sem perder de vista debates e perspectivas que permeiam a compreensão do capitalismo e, especificamente, da exploração do trabalho na atualidade.

Palavras-chave: plataformização, uberização, trabalho informal, trabalho online

\section{Digital platform work: perspectives from the global South}

\section{Abstract}

The dossier Digital platform work: perspectives from the global South aims to contribute to the analyzes carried out from the periphery and which recognize its centrality in contemporary global phenomena. That is, research that incorporates the specific structures of work in the periphery of the globe in their analysis, without losing sight of debates and perspectives that permeate the understanding of capitalism and, specifically, the exploitation of work today.

Keywords: platform labor, uberization, informal work, online work

* Universidade Estadual de Campinas, Campinas, SP, Brasil.

** Universidade Federal de São Paulo, Guarulhos, SP, Brasil.

*** Universidade do Vale do Rio dos Sinos, São Leopoldo, RS, Brasil. 


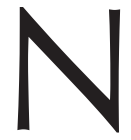
os últimos anos, a uberização e a plataformização vêm redefinindo a agenda de pesquisa da sociologia do trabalho e de outras áreas que pesquisam e estudam o trabalho. Pesquisadores e pesquisadoras de todo o mundo enfrentam os desafios para a compreensão e debate dessas temáticas, criando, revisando e atualizando teorias e conceitos, perante o avassalador desenvolvimento de processos que aprofundam a informalização do trabalho, incidem nas definições da jornada e do tempo de trabalho, transferem riscos e custos para os trabalhadores e trabalhadoras, contando com novos meios técnicos de difícil definição, assim como com novos modos de subjetivação. Dos países do Norte aos do Sul, o trabalho vem sofrendo e sendo alvo de ataques que passam por um conjunto de estratégias produtivas, gerenciais, tecnológicas, políticas e jurídicas que radicalizam a subordinação do trabalho e esgarçam os vínculos de solidariedade e de ação coletivas dos trabalhadores e das trabalhadoras nas mais variadas formações sociais. Dialeticamente, estruturam-se também novas formas de resistência - individuais, cotidianas e coletivas - e de organização política, também elas passíveis de serem apropriadas como elementos da gestão do trabalho.

A uberização e plataformização podem, então, ser compreendidas como parte de um processo de longa data, de ataques às forças sociais do trabalho que correm juntamente com novos arranjos produtivos, os quais não podem ser compreendidos de forma desvinculada da valorização financeira, nem dos processos de oligopolização e concentração de renda e de riqueza que marcam o neoliberalismo. Entretanto, se, por um lado, podemos identificar um tipo de organização do trabalho que se estabelece em nível global, é também necessário o desvendamento de suas determinações socioespaciais e de sua inserção na divisão internacional do trabalho. Ainda, as especificidades da periferia - onde a informalidade, a ausência de direitos e a flexibilidade são elementos estruturantes -, engrossam o caldo dos dilemas políticos e analíticos que seguem permeando a sociologia brasileira e hoje estão no cerne do debate sobre as plataformas digitais de trabalho. Nesse sentido, os artigos que, em conjunto, formam este dossiê 
procuram analisar as especificidades que conferem centralidade ao Sul no desvendamento das formas contemporâneas de acumulação e da reprodução social capitalistas.

Assim, o dossiê Trabalho em plataformas digitais: perspectivas desde o Sul global se organiza com o objetivo de trazer contribuições para as análises que se fazem a partir da periferia e reconhecem sua centralidade nos fenômenos globais contemporâneos. Trata-se, portanto, de pesquisas que incorporam as estruturas específicas do trabalho na periferia em sua análise, sem perder de vista debates e perspectivas que permeiam a compreensão do capitalismo e, especificamente, da exploração do trabalho na atualidade. Nesse sentido, este dossiê se propõe a fundamentar um olhar sociológico atento às transformações e permanências das formas de organização e controle do trabalho a partir do Sul, assim como às generalizações de elementos tipicamente periféricos, que parecem ganhar novos contornos globais. Entretanto, a perspectiva comum aos artigos é de que a generalização se realiza não de forma homogênea e, digamos, universalizada, mas de acordo com as especificidades nacionais - em outras palavras, com as desigualdades, injustiças e determinadas formas de reprodução social que nos possibilitam pensar as próprias categorias centro e periferia, ou, mais recentemente, Sul global.

O dossiê é aberto por seus organizadores - Ludmila Costhek Abílio, Henrique Amorim e Rafael Grohmann - com o artigo Uberização e plataformização do trabalho no Brasil: conceitos, processos e formas (Abílio et al., 2021). A partir de uma visada desde a periferia, os autores enfrentam os persistentes obscurecimentos e dilemas analíticos em torno da uberização. Destacando alguns aspectos das transformações do capitalismo contemporâneo, definem elementos centrais que permitem pensar a uberização como uma tendência global que envolve novos modos contemporâneos de controle e gerenciamento do trabalho. $\mathrm{O}$ argumento central, da perda de formas estáveis dos meios de gerenciamento, das regras, da definição do tempo e da jornada de trabalho, tece a compreensão das dificuldades atuais de fixar conceitos e categorias de análise. Os dilemas 
percorrem a nomeação do trabalho subordinado por meio de plataformas e chegam à própria definição de gig economy, tomada por eles como problemática para a realidade brasileira. São trazidos à tona os modos de vida periféricos para se discutir, por um lado, como os elementos que estruturam esses modos de vida são apropriados de novas maneiras racionalizadas, dataficadas e centralizadas - pelas empresas que exploram o trabalho por meio de plataformas digitais; por outro, a tendência à generalização desses elementos, especialmente, quando a informalidade se firma como regra no presente e futuro das relações de trabalho. Nesse contexto, antigas formas de produção são reconfiguradas e radicalizam bases estruturais de exploração.

Em Hunger for profit: how food delivery platforms manage couriers in China, Jenny Chan nos leva para o cotidiano dos trabalhadores de plataformas de entrega de alimentos na China. Indagando como é possível empresas gerenciarem seus trabalhadores por meio de contratação de serviços por peça e não de empregos, a autora aborda os dilemas da ausência de definição sobre jornada de trabalho, a variação da remuneração, a ausência de proteções legais que correm junto com o eficaz gerenciamento algorítmico do trabalho. Questões que a guiam: como este gerenciamento opera e como os entregadores experimentam o controle e a autonomia do trabalho? A análise é fruto de dois anos de pesquisa empírica com 32 homens imigrantes rurais que encontram no trabalho de entregador os meios para sobreviverem na capital Beijing. São trazidas as experiências desses trabalhadores que, na condição de migrantes não têm acesso a determinadas proteções e direitos sociais que outros cidadãos têm. É por meio dessa pesquisa que a autora nos detalha os sistemas de gerenciamento algorítmico, o monitoramento do trabalho emocional, os sistemas de vigilância e meios de controle, que envolvem avaliações e monitoramento feitos pelos consumidores, bloqueios, punições por parte das plataformas todos esses, elementos permanentes, mas também obscuros no cotidiano do trabalho. Chan (2021) mostra como esses trabalhadores informais estão 
lutando desesperadamente para sobreviver em um contexto de ausência de proteções legais em relação ao setor de entregas.

Da China para as Filipinas: em Performing "digital labor bayanihan": strategies of influence and survival in the platform economy, Cheryll Soriano, Earvin Charles Cabalquinto e Joy Hannah Panaligan discutem o papel dos chamados influenciadores no trabalho de diferentes plataformas, em especial, do trabalho de freelancers. Apresentando uma contextualização do platform labor nas Filipinas, as autoras demonstram como esses youtubers - ou "micro-celebrities" - agem como coachs informais. Fazendo pontes entre trabalhadores e plataformas, os influenciadores contribuem no estabelecimento das estratégias cotidianas que viabilizam essas atividades em meio à precariedade das condições de trabalho. Haveria, então, uma espécie de alinhamento entre o trabalho freelance por plataformas e uma espécie de "pop management" desempenhado por esses atores em seu trabalho de "micro-influencers". Na interpretação das autoras (Soriano et al., 2021), a produção discursiva aí desenhada ajuda a alimentar um espírito empreendedor da economia de plataformas nas Filipinas. Entretanto, uma promoção que é complexa, na medida em que a definição de bayanihan se origina de um sentido de comunidade e ajuda coletiva frente às adversidades vivenciadas por indivíduos. Nesse sentido, olhar para os influencers também envolve o reconhecimento do estabelecimento de um sentido de comunidade que incidirá na definição de estratégias individuais de sobrevivência, as quais também garantem a inserção social e reprodução desse tipo de trabalho. Na mesma esteira, o artigo destaca as ambiguidades, na agência dos trabalhadores, relativas às estratégias que se fazem na relação com as desigualdades estruturais locais sem de fato desafiá-las.

Os dois artigos seguintes tratam das chamadas plataformas de microtrabalho, situadas nos debates sobre a centralidade do trabalho e de sua suposta desnecessidade frente à inteligência artificial. Em Waiting for robots, Antonio Casilli questiona os mitos e imaginários em torno da automação e da substituição de trabalhadores por robôs. A partir da definição de trabalho digital como atividade humana dataficada e taskificada, ele 
desvenda a imprescindível participação do trabalho humano na produção da inteligência artificial e na automação. Estariam em jogo, então, os processos de invisibilização social que obscurecem a centralidade do trabalho no desenvolvimento e alimentação das novas tecnologias. Para estabilizar a definição de trabalho digital, o autor recorre à tipificação do trabalho em plataformas, classificando-o como trabalho sob demanda (on demand labor), microtrabalho (microwork) e trabalho em redes sociais (networked labor). É a partir dessas definições que o autor irá destrinchar diferentes atividades, modos de funcionamento e sua relação com os processos de automação. Também são analisados impactos da pandemia sobre cada uma dessas categorias. Chamando-nos para o conhecimento e reconhecimento das condições materiais do trabalho digital e dos tristes horizontes que se desenham para a força de trabalho global, talvez a tese central de Casilli (2021) seja a de que a automação está intrinsicamente relacionada com o trabalho "underpaid, micropaid e unpaid". O autor ainda destaca as desigualdades Norte-Sul em relação ao trabalho e à inteligência artificial, dado que a maioria das plataformas de microtrabalho se origina nos Estados Unidos, Europa, Coreia do Sul e Japão, enquanto a maioria de trabalhadores está no Sul global.

Na sequência, Matheus Viana Braz apresenta em Heteromação e microtrabalho no Brasil um panorama das plataformas de microtrabalho em nosso país. O artigo conceitua não só o microtrabalho, como também os diferentes tipos de atividades e plataformas presentes no Brasil. Para tanto, aborda os vários dilemas que nos remetem às indefinições sobre o que é e o que não é trabalho, assim como aos meios de rebaixamento dos custos do trabalho associados à sua fragmentação. As categorias de trabalho gratuito e trabalho não pago orientam a análise. Por esta perspectiva, o autor discute a participação do microtrabalho no engendramento de novas formas de extração de valor relacionadas à plataformização do trabalho. Mobilizado pela pergunta "onde estaria o Brasil na geopolítica do microtrabalho?", o autor (Viana Braz, 2021) faz uso da netnografia, trazendo também contribuições metodológicas importantes. O acompanhamento de vinte e dois grupos de 
Whatsapp e Facebook, durante meses, desdobra-se em caminhos analíticos que nos permitem ir da experiência cotidiana dos trabalhadores - tal como exposta e constituída nesses grupos - à compreensão dos modos de estruturação, gerenciamento e realização do que o autor denomina de mercado de microtarefas no Brasil. O artigo nega uma definição homogênea e estável de microtrabalho no país, evidenciando que este não pode ser compreendido de forma apartada das cadeias de produção globais.

Por fim, Sofía Scasserra e Flora Partenio em seu artigo Precarización del trabajo y estrategias de trabajadoras en plataformas digitales: trabajo desde el hogar, organización sindical y disputa por derechos en el contexto de la pandemia del Covid-19, tematizam a inserção das mulheres em trabalhos em plataformas. Tendo como foco analítico a Argentina, as autoras demonstram, com base em um mapeamento da presença das mulheres em plataformas digitais, como o trabalho - por exemplo, de microtarefas (remoto) - se apresentou como uma das poucas alternativas, dada a sobrecarga de trabalho domésticos que limita as possibilidades de emprego, a sua inserção no mercado de trabalho. Procurando retomar e aprofundar o histórico debate, acirrado no contexto da pandemia do Covid-19, sobre a crise dos cuidados, o artigo problematiza e evidencia a necessidade da constituição de novos direitos trabalhistas ao propor uma agenda sindical e feminista que não se esvaneça na virtualidade dos trabalhos remotos. Ao discutir a inserção das mulheres, e também do público LGBT+, que combina trabalhos remunerados e não remunerados, as autoras (Scasserra; Partenio, 2021) procuram demonstrar teórica e empiricamente a necessidade da promoção de estratégias políticas e sindicais que deem representatividade às suas reinvindicações. Explicitam, nesse sentido, como os trabalhos remotos acabam por, de um lado, apresentar-se como uma possibilidade de combinar tempos e tarefas remuneradas e não remuneradas, mas, de outro, limitam o trabalho das mulheres a setores e funções produtivas e de serviços economica e socialmente menos relevantes, relegando às mulheres a maioria de trabalhos nos quais o confinamento e o isolamento são características marcantes. 


\section{Referências}

1. ABÍLIO, Ludmila C.; AMORIM, Henrique; GROHMANN, Rafael. Uberização e plataformização do trabalho no Brasil: conceitos, processos e formas. Sociologias, v. 23, n. 57, p. 26-56, 2021.

2. CASILLI, Antonio. Waiting for robots. Sociologias, v. 23, n. 57, p. 112-133, 2021.

3. CHAN, Jenny. Hunger for profit: how food delivery platforms manage couriers in China. Sociologias, v. 23, n. 57, p. 58-82, 2021.

4. SCASSERA, Sofía; PARTENIO, Flora. Precarización del trabajo y estrategias de trabajadoras en plataformas digitales: trabajo desde el hogar, organización sindical y disputa por derechos en el contexto de la pandemia del Covid-19. Sociologias, v. 23, n. 57, p. 174-206, 2021.

5. SORIANO, Cheryll; CABALQUINTO, Earvin C.; PANALIGAN, Joy H. Performing "digital labor Bayanihan": strategies of influence and survival in the platform economy. Sociologias, v. 23, n. 57, p. 84-111, 2021.

6. VIANA BRAZ, Matheus. Heteromação e microtrabalho no Brasil. Sociologias, v. 23, n. 57, p. 134-172, 2021. 